\title{
Rituximab for the treatment of patients with chronic lymphocytic leukemia
}

\author{
This article was published in the following Dove Press journal: \\ Cancer Management and Research \\ 10 March 2010 \\ Number of times this article has been viewed
}

M Gentile
E Vigna
C Mazzone
E Lucia
AG Recchia
L Morabito'
MG Bisconte
C Gentile
F Morabito
'UOC di Ematologia, Azienda
Ospedaliera di Cosenza, Italy;
${ }^{2 S}$ Servicio de Hematología y
Hemoterapia, Hospital Universitario
de Canarias, La Laguna, Tenerife, Spain

Correspondence: Massimo Gentile Unità Operativa Complessa di Ematologia, Dipartimento di Medicina Interna,Azienda Ospedaliera di Cosenza, Viale della Repubblica , 87I00 Cosenza, Italy

Tel +390984 681329

Fax +390984 79175I

Email massim.gentile@tiscali.it

\begin{abstract}
Chronic lymphocytic leukemia (CLL) is a lymphoproliferative disorder that originates from antigen-experienced B lymphocytes that do not die and hence accumulate due to external survival signals or undergo apoptosis and are replenished by proliferating precursors. These neoplastic lymphocytes exhibit a characteristic immunophenotype of $\mathrm{CD}^{+} / \mathrm{CD} 19^{+} / \mathrm{CD} 20^{+} /$ HLA-DR+/CD23 $/$ sIgdim. Thus, the CD20 antigen has been an appealing target for therapy. The introduction of the monoclonal antibody rituximab (anti-CD20) enabled an outstanding advance in CLL treatment. The introduction of this monoclonal antibody into chemotherapy regimens has dramatically improved complete response rates and progression-free survival in patients with both untreated and relapsed CLL. Although only preliminary data from phase III confirmatory trials have been reported, the FCR regimen, which combines fludarabine and cyclophosphamide with rituximab, is currently the most effective treatment regimen for CLL patients, and has also been demonstrated to significantly improve overall survival. The success of rituximab and the identification of other CLL lymphocyte surface antigens have spurred the development of a multitude of monoclonal antibodies targeting distinct proteins and epitopes in an attempt to target CLL cells more effectively.
\end{abstract}

Keywords: rituximab, chronic lymphocytic leukemia, chemotherapy

\section{Introduction}

Chronic lymphocytic leukemia (CLL) represents the most frequent form of leukemia in the Western Hemisphere. The worldwide incidence of CLL ranges between 0 and 5.5 cases per 100,000 people per year. ${ }^{1}$ The median age at presentation is approximately 72 years, but $20 \%$ of patients present the disease before the age of 55 years. ${ }^{2,3}$ Although the overall median survival is approximately 10 years, the clinical course and prognosis of CLL are extremely heterogeneous: some patients never require treatment and have a survival similar to that of healthy age-matched individuals, whereas others have a poor prognosis and an early treatment requirement. Until the early 1980s, chlorambucil, which enabled only palliative therapy of the disease, represented the primary treatment for CLL. Subsequently, fludarabine, a purine analog, was introduced into the array of therapies for CLL. This drug showed a better debulking activity and an advantage in terms of progression-free survival (PFS) compared with chlorambucil. ${ }^{4-8}$ With the aim of increasing its efficacy, fludarabine has been subsequently associated with other chemotherapeutic agents. Over the past decade the therapy for CLL has changed significantly with the introduction of monoclonal antibodies as well as rituximab (a chimeric anti-CD20 antibody) and alemtuzumab (a humanized anti-CD52 antibody). Rituximab, initially administered as a single agent in relapsed/refractory 
CLL patients, showed a limited activity. ${ }^{9-12}$ Although phase II studies demonstrated that the addition of rituximab to fludarabine-based chemotherapy improved complete response $(\mathrm{CR})$ rates and PFS in both previously untreated and relapsed patients. ${ }^{13-27}$ This review focuses specifically on the development and current applications of rituximab in the treatment of CLL.

\section{Mechanism of action}

CD20 antigen is a calcium channel that interacts with the B-cell immunoglobulin receptor complex. ${ }^{28} \mathrm{CD} 20$ is expressed on $>90 \%$ of B-cell non-Hodgkin's lymphomas (NHL), ${ }^{29,30}$ but occurs at lower density on CLL lymphocytes. ${ }^{31,32}$ Rituximab, a genetically engineered mouse/human chimeric IgG1- $\kappa$ monoclonal antibody, ${ }^{33}$ is able to kill both neoplastic and normal B-cells expressing CD20 through indirect and direct cytotoxic mechanisms. ${ }^{34,35}$ Indirect mechanisms are complement-dependent cytotoxicity (CDC) and antibody-dependent cell-mediated cytotoxicity (ADCC). Direct mechanisms, although less defined, have also been reported and include growth inhibition, induction of apoptosis and chemosensitization. ${ }^{34,35}$ CDC determines tumor cell lysis and increases phagocytosis deriving from activation of the complement cascade by the Fc portion of antibody bound to the neoplastic lymphocytes. ${ }^{34,35}$ The engagement of effector cells with active Fc receptors determines antibody-coated tumor cell death resulting in ADCC. ${ }^{34,35}$ The relative importance of the ADDC has been demonstrated by Cartron et al, who showed an association between polymorphism of the $\mathrm{IgG}$ Fc receptor Fcgamma RIIIa gene and response to rituximab. ${ }^{36}$ Nonetheless, this association seems to be lost when rituximab is used in combination with or after chemotherapy. ${ }^{37}$ Moreover it seems that the mechanisms of action of the rituximab depend on the tumor site. ${ }^{35}$ For example, ADCC and CDC are implicated in the killing of neoplastic cells circulating in the blood, while these mechanisms are probably less important for lymph node or extranodal sites. ${ }^{35}$ Furthermore CD55, CD59, CD20 and the complement seem to play important roles in rituximabinduced cytotoxicity by a caspase-independent process producing reactive oxygen species. ${ }^{34,35}$ Finally, rituximab induces apoptosis through activation of caspase-3 and sensitizes cells to proapoptotic stimuli. ${ }^{34,35}$

In vitro data show that rituximab sensitises neoplastic cells to the effects of chemotherapeutic drugs, thus supporting the use of combination chemotherapy with rituximab. ${ }^{34}$ For example it seems that in vitro rituximab downregulates interleukin (IL)-10 and bcl-2 expression, making neoplastic B cells potentially more susceptible to fludarabine-induced apoptosis. ${ }^{38}$ Although there is a large variability of responses, rituximab resistance is a rare event. Experimental and clinical data support the role of tumor burden and rituximab exposure in the variability of the responses observed, McLaughlin et al showed that serum rituximab levels were sustained longer in patients with lower tumor burden and after the fourth infusion rather than after the first. ${ }^{39}$ These data have been confirmed by Daydé et al who reported that in mice rituximab concentrations were inversely correlated with tumor burden, and using a pharmacokinetic-pharmacodynamic model, they demonstrated that tumor burden significantly influenced rituximab efficacy. ${ }^{40}$ Moreover, O'Brien et al showed that rituximab was more efficacious at higher doses in CLL patients. Finally, other authors have demonstrated that it is possible to enhance rituximab efficacy through upregulation of CD20 antigen expression on tumor cells from CLL patients by cytokines such as IL-4, granulocyte-macrophage colony-stimulating factor (GM-CSF) and tumour necrosis factor- $\alpha(\mathrm{TNF}-\alpha)^{34}$ More recently, resistance to rituximab was dramatically overcome enhancing complement activity, which has been demonstrated to be depressed in roughly half CLL patients ${ }^{41}$ by concurrent administration of fresh frozen plasma. ${ }^{42}$

\section{Single-agent rituximab therapy}

In phase I studies rituximab was administered at various doses (single dose ranging from 10 to $500 \mathrm{mg} / \mathrm{m}^{2}$ or 4 doses ranging from 125 to $375 \mathrm{mg} / \mathrm{m}^{2}$ weekly) in relapsed indolent NHL patients. ${ }^{43,44}$ Although both optimal dose and dose-limiting toxicity of rituximab have not been identified, the dose of $375 \mathrm{mg} / \mathrm{m}^{2}$ weekly for 4 weeks has been empirically chosen for subsequent studies. ${ }^{39,45,46}$ This schedule has been approved by the United States Food and Drug Administration (FDA) for the treatment of low grade NHL. In a pivotal phase II study, $50 \%$ of patients affected by follicular lymphoma achieved at least a partial remission (PR), while poor results were observed in relapsed/refractory small lymphocytic lymphoma (SLL) or CLL cases: overall response rate (ORR) 13\% (4/30 patients). ${ }^{47}$ Similar modest results have been reported in other small trials in which rituximab was administered as single-drug to treat relapsed CLL patients. ${ }^{9,47-51}$ Although a high discrepancy in terms of ORR (range 0\%-90\%) has been observed in these trials (Table 1), possibly due to the small number of enrolled cases and the higher number of rituximab doses administered in the study reported by Thomas et al (ORR: 90\%), a short PFS has been noted in all studies..$^{9,47-51}$ Since it has been assumed that the poor results achieved with single-agent rituximab were due 
Table I Phase II trials of single-agent rituximab in chronic lymphocytic leukemia patients

\begin{tabular}{|c|c|c|c|c|c|}
\hline Authors & $\begin{array}{l}\text { No of evaluable } \\
\text { patients }\end{array}$ & Prior therapy & $\begin{array}{l}\text { Rituximab } \\
\text { dose }\left(\mathrm{mg} / \mathrm{m}^{2}\right)\end{array}$ & No of doses & $\begin{array}{l}\text { Overall response } \\
\text { rate }(\%)\end{array}$ \\
\hline McLaughlin et a ${ }^{147}$ & 30 & Yes & 375 q 4 weeks & 4 & 13 \\
\hline Nguyen et a ${ }^{48}$ & 10 & Yes & 375 q 4 weeks & 4 & 10 \\
\hline Winkler et $\mathrm{al}^{49}$ & 9 & Yes & 375 q 4 weeks & 4 & II \\
\hline Ladetto et $\mathrm{a}^{50}$ & 7 & Yes & 375 q 4 weeks & 4 & 0 \\
\hline Huhn et $\mathrm{al}^{9}$ & 28 & Yes & 375 q 4 weeks & 4 & 25 \\
\hline Thomas et $\mathrm{al}^{52}$ & 21 & No & 375 q 4 weeks & 8 & 90 \\
\hline Itala et $\mathrm{al}^{51}$ & 24 & Yes & 375 q 4 weeks & 4 & 35 \\
\hline Hainsworth et $\mathrm{al}^{10}$ & 44 & No & 375 q 4 weeks & 4 & 51 \\
\hline
\end{tabular}

to low CD20 expression on the surface of neoplastic CLL lymphocytes, in subsequent studies the efficacy of both higher number of cycles and higher dose of rituximab have been verified. Forty-four untreated CLL/SLL patients with at least one indication for therapy received $375 \mathrm{mg} / \mathrm{m}^{2}$ of rituximab weekly for 4 weeks and additional 4 -week courses every 6 months for up to 4 cycles only for patients with objective response or stable disease..$^{10}$ The ORR after the first course of rituximab was $51 \%$ ( $4 \% \mathrm{CR}$ ). Twenty-eight patients received one or more additional courses of rituximab. The ORR was $58 \%$ (CR 9\%) and the 2-year PFS was 49\%. ${ }^{10}$ Subsequently Thomas et al tested the activity of 8 courses of rituximab at standard dosage of $375 \mathrm{mg} / \mathrm{m}^{2}$ weekly in 31 early stage (Rai 0-II) CLL patients with high beta 2-microglobulin and without indication for therapy. Approximately $90 \%$ of patients achieved at least a PR and $19 \%$ a CR. ${ }^{52}$ In an attempt to improve ORR, two dose-escalation studies have been conducted. The M.D. Anderson Cancer Center (MDACC) group escalated the rituximab dose from $350 \mathrm{mg} / \mathrm{m}^{2}$ to $2250 \mathrm{mg} / \mathrm{m}^{2}$ in 40 previously treated CLL cases and in 10 other B-cell leukemias $(\mathrm{n}=10) .{ }^{11}$ The ORR was $40 \%$ (in CLL $36 \%$, all
PR) and response was correlated with dose: $22 \%$ for patients treated from 500 to $825 \mathrm{mg} / \mathrm{m}^{2}$ vs $75 \%$ for those treated at the highest dose of $2250 \mathrm{mg} / \mathrm{m}^{2}(P=0.007) .{ }^{54}$ Instead Byrd et al reported data relative to the efficacy of a schedule of rituximab given at $375 \mathrm{mg} / \mathrm{m}^{2} 3$ times per week for 4 weeks. ${ }^{12}$ In 33 patients enrolled with previously treated SLL/CLL the ORR was $45 \%$. Nevertheless, patients with del(17p) failed to achieve a single response..$^{53}$ In all these studies rituximab showed a good activity in reducing peripheral blood disease, while in bulky nodal disease it was less effective. ${ }^{9-12,50-52}$ Moreover, when given at high doses rituximab is more efficacious, because as a single-agent it does not seem to affect the prognosis of CLL patients.

\section{Rituximab in combination with chemotherapy}

In the light of the results of several randomized studies in B-cell NHL patients in which rituximab in combination with different chemotherapy drugs achieved an improvement in terms of ORR and overall survival (OS), this monoclonal antibody was also used in combination with chemotherapy

Table 2 Phase II rituximab-based chemoimmunotherapy regimens in chronic lymphocytic leukemia patients

\begin{tabular}{|c|c|c|c|c|c|c|c|}
\hline Authors & $\begin{array}{l}\text { No of } \\
\text { evaluable } \\
\text { patients }\end{array}$ & Prior therapy & $\begin{array}{l}\text { Chemotherapy } \\
\text { agents }\end{array}$ & $\begin{array}{l}\text { Rituximab } \\
\text { dose }\left(\mathrm{mg} / \mathrm{m}^{2}\right)\end{array}$ & $\begin{array}{l}\text { No of } \\
\text { cycles }\end{array}$ & $\begin{array}{l}\text { Overall } \\
\text { response } \\
\text { rate (\%) }\end{array}$ & CR rate (\%) \\
\hline Byrd et $\mathrm{al}^{13}$ & 51 & No & Flu & 375 q 4 weeks & 6 & 90 & 47 \\
\hline Schulz et al ${ }^{18}$ & 31 & No & Flu & 375 q 4 weeks & 4 & 87 & 32 \\
\hline Wierda et $\mathrm{a}^{16}$ & 177 & Yes & $\mathrm{Flu}+\mathrm{Cy}$ & 500 q 4 weeks & 6 & 73 & 25 \\
\hline Keating et $\mathrm{al}^{15}$ & 300 & No & $\mathrm{Flu}+\mathrm{Cy}$ & 500 q 4 weeks & 6 & 94 & 72 \\
\hline Kay et $\mathrm{a}^{26}$ & 64 & No & Pent + Cy & 375 q 4 weeks & 6 & 91 & $4 \mid$ \\
\hline Bosch et $\mathrm{a}^{23}$ & 68 & No & $\mathrm{Flu}+\mathrm{Cy}+\mathrm{Mito}$ & 500 q 4 weeks & 6 & 93 & 82 \\
\hline Faderl et $\mathrm{a}^{24}$ & 30 & No & $\mathrm{Flu}+\mathrm{Cy}+\mathrm{Mito}$ & 500 q 4 weeks & 6 & 96 & 83 \\
\hline
\end{tabular}

Abbreviations: CR, complete response; Flu, fludarabine; Cy, cyclophosphamide; Pent, pentostatin; Mito, mitoxantrone. 
agents in CLL cases (Table 2). In the 9712 study the Cancer and Leukemia Group B (CALGB) randomized 104 previously untreated CLL patients to receive fludarabine at a standard dose ( $25 \mathrm{mg} / \mathrm{m}^{2}$ days $1-5$ monthly for 6 cycles) with (fludarabine arm) or without concurrent rituximab $375 \mathrm{mg} / \mathrm{m}^{2}$ on day 1 (also on day 4 of the first cycle), followed by rituximab $375 \mathrm{mg} / \mathrm{m}^{2}$ weekly for 4 weeks starting 8 weeks after completion of fludarabine. ${ }^{13}$ The patients enrolled in the fludarabine arm achieved both higher ORR (90\% vs $77 \%$ ) and $\mathrm{CR}$ rates ( $47 \%$ vs $28 \%$ ) than those enrolled in the sequential arm. The median response duration and survival was not achieved for either regimen. Although patients with high-risk CLL characterized by unmutated IgVH, $\operatorname{del}(17 p)$ or del(11q) undergoing chemoimmunotherapy achieved $\mathrm{CR}$ as well as patients with good risk CLL, they showed a shorter PFS and OS. ${ }^{17}$ To assess the effect of the addition of rituximab to fludarabine therapy Byrd et al retrospectively compared the outcome of CLL patients enrolled in two multicenter clinical trials in which fludarabine and rituximab (CALGB 9712, $\mathrm{n}=104$ ) or fludarabine alone (CALGB 9011, $\mathrm{n}=178$ ) were administered. ${ }^{14}$ This study showed that patients receiving fludarabine and rituximab had a significantly better ORR ( $84 \%$ vs $63 \%$ ), CR ( $38 \%$ vs $20 \%$ ), as well as a 2 -year PFS (67\% vs $45 \%)$ and 2 -year OS (93\% vs $81 \%$ ) than patients receiving fludarabine alone. ${ }^{14}$

Similar data have been reported by Schulz et al, who treated 31 CLL patients with a combination of fludarabine (25 mg/m $\mathrm{m}^{2}$ days $1-5$ monthly for 6 cycles) and rituximab ( $375 \mathrm{mg} / \mathrm{m}^{2}$ on day 1 of cycles 3-6). ${ }^{18}$ Similar ORR and CR have been observed in previously treated (ORR 91\%, CR $45 \%$ ) and untreated patients (ORR $85 \%$, CR 25\%). Thirtytwo infections have been registered, and 1 patient died of cerebral hemorrhage due to thrombocytopenia. ${ }^{18}$

On the basis of the efficacy of chemoimmunotherapy and of the combination of fludarabine and cyclophosphamide ${ }^{54}$ the MDACC group assessed the effectiveness of the FCR schedule (fludarabine $25 \mathrm{mg} / \mathrm{m}^{2}$, cyclophosphamide $250 \mathrm{mg} / \mathrm{m}^{2}$ days $1-3$, and rituximab $375 \mathrm{mg} / \mathrm{m}^{2}$ on day 1 of cycle 1 and $500 \mathrm{mg} / \mathrm{m}^{2}$ on day 1 of cycles $2-6$, monthly for 6 cycles). In 177 relapsed or refractory CLL patients an ORR of $73 \%$ with $25 \%$ of CR was achieved. ${ }^{16}$ Thirty-two percent of patients in CR also showed a complete molecular response. ${ }^{16}$ In 300 untreated CLL patients an ORR of $95 \%$ with a remarkable CR rate of $72 \%$ has been reported. ${ }^{15}$ Six-year OS and failure-free survival were $77 \%$ and $51 \%$, respectively, with a median time to progression of 80 months. ${ }^{19}$ In a multivariate analysis of patients receiving fludarabine-based therapy at MDACC, the FCR schedule was the strongest independent determinant of survival. ${ }^{19}$ In the trial conducted by the German CLL Group in which FCR was compared with FC, patients enrolled on the FCR arm showed higher response rates and PFS compared to those of the FC arm. ${ }^{20}$ Although FCR caused more neutropenia/leukopenia the incidence of severe infections was not statistically different. ${ }^{20}$ Recently, statistically significant differences were observed in OS between the two treatment arms. The OS rate at 37.7 months was $84.1 \%$ in the FCR arm vs $79.0 \%$ in the FC $\operatorname{arm}(P=0.01)$. Notably, only patients in Binet stages A and B showed a superior OS after FCR treatment (Binet A: HR 0.19, CI 95\%, 0.023-1.613, $P=0.09$; Binet B: HR 0.45, CI 95\%, 0.296-0.689, $P<0.001$; Binet C HR1.4, CI 95\%, 0.843-2.620, $P=0.168$ ). Notably, FCR is the unique first-line combination chemotherapy able to improve OS in CLL, corroborating the recommendation to use FCR as standard therapy in physically fit patients with CLL requiring therapy. Age, sex, FCR-treatment, response, number of cycles (0-3), 17p-deletion, increased serum levels of thymidine kinase and beta 2-microglobulin and unmutated IGVH genes were independent prognostic factors predicting OS or PFS. ${ }^{20}$ The MDACC group also evaluated the prognostic relevance of biological markers in patients treated with chemoimmunotherapy regimens. Although this approach appears to overcome the adverse prognostic impact of del(11q), ${ }^{55}$ it does not seem to modify the poor prognosis of cases with unmutated IgVH status. ${ }^{56}$

Based on the high responses as well as the associated toxicities observed in patients treated with FCR, Foon et al tested a dose-reduced version of FCR..$^{21}$ With the intent of maintaining efficacy they reduced fludarabine to $20 \mathrm{mg} / \mathrm{m}^{2}$, and cyclophosphamide to $150 \mathrm{mg} / \mathrm{m}^{2}$, while rituximab was increased to $500 \mathrm{mg} / \mathrm{m}^{2}$ on days 1 and 14 of a 28 -day cycle. This schedule was followed by rituximab maintenance after completion of 6 cycles. In the 48 assessable patients the ORR was $100 \%$ with a CR rate of $79 \%$ (38 patients); $37 / 38$ patients in CR achieved a flow-cytometric CR. Median duration of CR was 22.3 months and none of the complete responders had relapsed at the time of report. Grade 3-4 neutropenia was noted in $13 \%$ of the cycles of therapy. The authors concluded that their regimen (FCR-Lite) maintained the high response rate of the FCR regimen, with a lower toxicity. ${ }^{21}$ With the aim of reducing the myelosuppression and immunosuppression due to the FCR regimen, La Manna et al recently explored the efficacy and safety of a sequential treatment strategy with fludarabine $25 \mathrm{mg} / \mathrm{m}^{2}$ on days $1-5$ every 4 weeks for 6 cycles, followed by consolidation with cyclophosphamide $3000 \mathrm{mg} / \mathrm{m}^{2}$ administered every 3 weeks for 3 cycles, followed by consolidation with weekly rituximab $375 \mathrm{mg} / \mathrm{m}^{2}$ 
for 4 cycles $\left(\mathrm{F}>\mathrm{C}>\mathrm{R}>\right.$ ). ${ }^{23}$ In the 36 previously untreated CLL patients enrolled in the study the ORR was $89 \%$ (CR $61 \%)$. Moreover 20 patients (56\%) achieved flow cytometric CRs, and 12 patients (33\%) achieved a molecular CR; 5 -year survival rate was $71 \%$ and $90 \%$ patients in molecular CRs remain in clinical CR at 5 years. Grade 3 or 4 neutropenia occurred in 32 patients ( $89 \%$ ), major infectious complications occurred in only 5 patients (14\%). Although this regimen seems to be safe and efficacious, only a randomized study could establish whether this schedule is superior in terms of response and toxicity to FCR. ${ }^{22}$

On the light of the good results obtained with the chemotherapy-only regimen of fludarabine, cyclophosphamide, and mitoxantrone (FCM), the Spanish group tested a new chemoimmunotherapy combination in 72 untreated CLL cases: rituximab plus FCM (R-FCM) followed by maintenance with rituximab $375 \mathrm{mg} / \mathrm{m}^{2}$ every 3 months for 2 years for patients who achieved a response. ${ }^{23}$ The ORR was $93 \%$, with molecular negative CR and molecular positive CR of $46 \%$ and $36 \%$, respectively. Thirteen percent of patients developed a severe neutropenia and a major infection was reported in $8 \%$ of cycles. Advanced clinical stage, del(17p), or increased serum beta 2-microglobulin levels correlated with a lower response rate. ${ }^{23} \mathrm{~A}$ similar schedule has been tested by the MDACC group in 30 previously untreated patients aged $<70$ years. ${ }^{24}$ Although similarly good results have been reported, they showed that, compared to a historical group of FCR-treated patients, there were no significant differences in term of response and toxicities between the two schedules. ${ }^{24}$

Moreover, rituximab has been combined with other purine analogues. La Manna et al have evaluated the efficacy and safety of combination of pentostatin $4 \mathrm{mg} / \mathrm{m}^{2}$, cyclophosphamide $600 \mathrm{mg} / \mathrm{m}^{2}$, and rituximab $375 \mathrm{mg} / \mathrm{m}^{2}$ administered on the same day every 21 days for 6 cycles in 46 relapsed/refractory patients (32 CLL and 14 other low-grade B-cell neoplasms). ${ }^{25}$ Supportive measures included filgrastim, sulfamethoxazole/trimethoprim, and acyclovir. Patients with CLL achieved an ORR of 75\% (CR rate $25 \%$ ); median survival was 44 months. Toxicity was acceptable, with grade 3-4 infections in $28 \% .{ }^{25}$ Based on these results, 65 previously untreated CLL patients were treated with a schedule combining rituximab $375 \mathrm{mg} / \mathrm{m}^{2}$, pentostatin $2 \mathrm{mg} / \mathrm{m}^{2}$, and cyclophosphamide $600 \mathrm{mg} / \mathrm{m}^{2}$ given on day 1 , then every 21 days for 6 cycles. Filgrastim was administered beginning on day $3 .{ }^{26}$ Seventy-one percent of patients were IgVH unmutated, $34 \% \mathrm{CD} 38$ positive and $34 \%$ ZAP-70 positive. Only $16 \%$ of treatment cycles had reported a grade 3-4 neutropenia, and $2 \%$ a grade 3-4 infection. ORR was 91\% (CR 41\%); median PFS was 33 months. ${ }^{26}$ Patients with del(17p) showed poor response to this schedule. Moreover, although $28 \%$ of patients were $\geq 70$ years of age, the efficacy and safety of this schedule was not significantly affected by age or renal function. ${ }^{27}$

Knauf et al showed bendamustine superiority over chlorambucil both in terms of OR and PFS in untreated CLL patients. ${ }^{57}$ More recently, bendamustine has been combined with rituximab (BR) in 117 patients with untreated CLL. ${ }^{58}$ Patients received $90 \mathrm{mg} / \mathrm{m}^{2}$ of bendamustine on day 1 and 2, combined with $375 \mathrm{mg} / \mathrm{m}^{2}$ and $375 \mathrm{mg} / \mathrm{m}^{2}$ of rituximab on day 1 of the first cycle and $500 \mathrm{mg} / \mathrm{m}^{2}$ on day 1 of subsequent cycles administered every 28 days for up to 6 cycles. Grade 3-4 neutropenia and thrombocytopenia occurred in $6.5 \%$ and $6.1 \%$ of all given courses, respectively. Twenty-nine episodes of CTC grade $\geq 3$ infections were documented. The ORR was $90.9 \%$ with $32.7 \%$ of $\mathrm{CR} .{ }^{58}$ Based on these encouraging data the German CLL Study Group decided to compare BR to FCR in a phase III trial (CLL10 protocol).

Promising results have been reported by Castro et al who evaluated rituximab in combination with high-dose methylprednisolone (HDMP) in 28 CLL patients. ${ }^{59}$ All patients received HDMP $1 \mathrm{~g} / \mathrm{m}^{2}$ iv days $1-3$ of each cycle, $16 / 28$ patients received 12 doses of rituximab at $375 \mathrm{mg} / \mathrm{m}^{2}$ weekly over three 4 -week cycles, while $12 / 28$ patients 9 doses of rituximab at $750 \mathrm{mg} / \mathrm{m}^{2}$. The treatment was well tolerated and only 4 major infections were registered. The ORR was $96 \%$ and 9 patients (32\%) achieved a CR, 2 of which were without minimal residual disease (MRD). Furthermore no significant difference in CR rates for patients $\geq 70$ years, or those with adverse cytogenetics, unmutated IGHV genes or high expression of ZAP-70 or CD38 was observed. ${ }^{59}$

Considering that 1) TNF- $\alpha$ determined infusion toxicity when thrice weekly rituximab was administered; 2) TNF- $\alpha$ inhibits CLL cell death by upregulating bcl- 2 and other antiapoptotic proteins; and 3) TNF- $\alpha$ upregulates CD55 and CD59 antigens, ${ }^{60-64}$ a combination schedule that combines etanercept, a TNF- $\alpha$ blocking agent, and rituximab was tested in relapsed CLL ${ }^{65}$ The 36 enrolled patients received etanercept $25 \mathrm{mg}$ subcutaneously twice weekly (weeks $1-5$ ) and rituximab $375 \mathrm{mg} / \mathrm{m}^{2}$ intravenously thrice weekly (weeks $2-5$ ). Of the 34 evaluable patients, 10 (29\%) responded, including 9 PR and 1 CR. No patients with del(17p) achieved a response. Median PFS for responsive patients. Grade 3 infections were registered in $14 \%$ of the patients. ${ }^{65}$ 


\section{Combination immunotherapy with rituximab and alemtuzumab}

Since rituximab and alemtuzumab target different antigens on the surface of B-cells and the former is effective on nodal disease while alemtuzumab has proven better activity in depleting CLL cells in the peripheral blood and in the bone marrow, ${ }^{66}$ these two monoclonal antibodies have been combined for the treatment of CLL patients. In 2003 Faderl et al reported data on the safety and efficacy of the combination of rituximab with alemtuzumab in 48 patients affected by relapsed/refractory lymphoproliferative disorders (32 with CLL, 9 with CLL/prolymphocytic leukemia [PLL], 1 with PLL, 4 with mantle cell leukemia/lymphoma, and 2 with Richter transformation). ${ }^{67}$ The schedule consisted of rituximab at a dose of $375 \mathrm{mg} / \mathrm{m}^{2}$ weekly for 4 weeks and alemtuzumab given at the loadingdose schedule of $3 \mathrm{mg}, 10 \mathrm{mg}$ and $30 \mathrm{mg}$ on 3 consecutive days during the first week of treatment, followed by a dose of $30 \mathrm{mg}$ on days 3 and 5 of weeks $2-4$. Although patients could receive a second cycle depending on response and toxicities, only 7 (15\%) did so. All patients received prophylaxis for Pneumocystis carini (Pneumocystis jiroveci) and CMV. ORR was $52 \%$ among the 32 patients with CLL 63\% (2 CLL patients achieved a CR); median time to progression was 6 months and median OS was 11 months. Most toxicities were grade 1-2 and infusion-related, and infections occurred in 52\% of the patients. Only $15 \%$ of patients showed a symptomatic CMV reactivation and required therapy. ${ }^{67}$ Zent et al have evaluated the combination of rituximab and alemtuzumab as early treatment in high-risk CLL patients. ${ }^{68}$ Thirty untreated CLL patients, who had no NCI criteria for treatment and with at least 1 marker of high-risk disease [del(17p), del(11q), or a combination of unmutated $\mathrm{IgVH}$ and $\left.\mathrm{CD} 38^{+} / \mathrm{ZAP} 70^{+}\right]$received subcutaneous alemtuzumab with dose escalation $(3 \mathrm{mg}, 10 \mathrm{mg}$, $30 \mathrm{mg}$ ) over 3 consecutive days, and then received $30 \mathrm{mg}$ daily 3 days per week and rituximab at $375 \mathrm{mg} / \mathrm{m}^{2}$ on day 8 and then repeated weekly for 4 weeks. All patients received $P$. carini and herpes virus prophylaxis and were monitored for CMV. Only 1 patient showed a major infection. CMV reactivation occurred in 3 patients (10\%) and 1 patient required hospitalization for symptomatic CMV infection. ORR was $90 \%$ with $37 \%$ of CR. Six patients (29\%) achieved a flow cytometric remission. Median response duration was 14.4 months. Finally, study patients had a significantly longer time from diagnosis to first treatment for CLL, according to conventional indications, than a comparison cohort with similar biologic risk profiles. Nonetheless, although this schedule showed a high efficacy in early stage CLL patients with poor prognosis it was not curative and most patients progressed. ${ }^{68}$

\section{Rituximab in combination with chemotherapy and immunotherapy}

With the aim of improving CR rates and eliminating MRD in order to prolong PFS and OS the MDACC group tested the activity and safety of the combination of alemtuzumab with the FCR regimen. ${ }^{69}$ Seventy-nine heavily pretreated CLL patients received cyclophosphamide $250 \mathrm{mg} / \mathrm{m}^{2}$ on days 3-5; fludarabine $25 \mathrm{mg} / \mathrm{m}^{2}$ on days 3-5; alemtuzumab $30 \mathrm{mg}$ iv on days 1,3 and 5 , and rituximab $375-500 \mathrm{mg} / \mathrm{m}^{2}$ on day 2 (CFAR), each 28 days for 6 courses. Antibiotic prophylaxis was trimethoprim/sulfamethazole and valacyclovir or valgancyclovir during treatment for 2 months after completion. ORR was $65 \%$ (CR 24\%); median time to progression for all responders was 26 months (32 months for CR and 18 months for PR pts). Patients with unfavorable cytogenetics [del(17p) (16), del(11q) (15), complex (5), and del(6q) (1)] achieved 14\% CR and 50\% PR. Prophylactic valgancyclovir was significantly more effective in preventing CMV reactivation $(3 / 30$ patients, $10 \%)$ than prophylactic valacyclovir (25/48 patients, 52\%). CMV reactivation requiring treatment occurred in 12 patients. The incidence of major infections $(11 \%)$ was similar to that observed with FCR in the relapsed setting. ${ }^{69}$ Given these promising results, the MDACC group is conducting an ongoing phase II study of CFAR as frontline treatment for patients with high-risk CLL. ${ }^{70}$ Since patients $<70$ years old and with beta 2-microglobulin $\geq 4$ when treated with FCR showed a CR rate and estimated median PFS significantly lower then similaraged patients with beta 2-microglobulin $<4$, for this subgroup of poor prognosis patients the CFAR has been proposed as frontline approach. ${ }^{70}$ In this study of 21 patients evaluable for response, ORR was 95\% (CR 71\%). All responder patients but one were free of disease in the bone marrow by flow cytometry. There was no significant correlation between response rate and quality of response and biological markers (IgVH mutation status, FISH status, or ZAP70 or CD38 expression). Major infections were seen in $2 \%$ of courses. CMV reactivation occurred in $2 / 21$ patients, both of whom received valacyclovir prophylaxis during treatment. In conclusion, CFAR is an active and promising frontline regimen in higher-risk CLL patients. ${ }^{70}$ Instead, Byrd et al have recently reported data about the efficacy and safety of the addition of lumiliximab, an anti-CD23 monoclonal antibody, to FCR therapy for the treatment of refractory or relapsed CLL patients. Thirty-one patients received either $375 \mathrm{mg} / \mathrm{m}^{2}$ $(\mathrm{n}=3)$ or $500 \mathrm{mg} / \mathrm{m}^{2}(\mathrm{n}=28)$ of lumiliximab in combination with FCR for 6 cycles. ORR was $65 \%$ with $52 \%$ of CR; estimated median PFS for all responders was 28.7 months. 
The toxicity profile was similar to that previously reported in relapsed CLL patients treated with FCR. ${ }^{71}$ The addition of lumiliximab to FCR therapy was safe and efficacious and did not seem to enhance toxicity in previously treated CLL patients. A randomized trial comparing lumiliximab plus FCR with FCR alone is underway to define the benefit of this combination in relapsed patients.

\section{Newer applications}

Taking into account that the average age at first diagnosis of CLL is about 72 years and patients treated with FCR regimen have a high risk of experiencing serious infectious complications, this regimen is an appropriate option only in a minority of CLL cases. Thus, considering that in the elderly population chlorambucil as a single drug is not inferior to fludarabine in terms of PFS and $\mathrm{OS}^{72,73}$ and that chlorambucil shows low toxicity, low cost and convenience as an oral drug, three ongoing trials (one Italian, one German and one English) have been testing the safety and efficacy of combination of rituximab with chlorambucil as first-line therapy for unfit CLL patients.

Since rituximab maintenance therapy provides a significant PFS benefit in patients with indolent B-cell $\mathrm{NHL}^{74,75}$ and considering that patients with SLL and CLL who had shown at least a stable disease after rituximab induction therapy could be successfully retreated at 6-month intervals, ${ }^{10}$ Del Poeta et al tested the efficacy of anti-CD20 consolidation/maintenance therapy in CLL patients. ${ }^{76}$ For induction treatment, all patients received daily fludarabine (25 $\mathrm{mg} / \mathrm{m}^{2}$ ) on days $1-5$ at 28-day intervals for a total of 6 cycles and those with at least a stable disease underwent consolidation/maintenance with 4-monthly cycles of rituximab at a dose of $375 \mathrm{mg} / \mathrm{m}^{2}$ followed by 12-monthly doses of rituximab at a dose of $150 \mathrm{mg} / \mathrm{m}^{2}$. All patients experienced a long PFS from the end of induction treatment (73\% at 5 years); moreover consolidation and maintenance therapy with rituximab prolonged response duration significantly in $\mathrm{CR}$ or PR cases positive for MRD. ${ }^{76}$ The efficacy of rituximab as post-remissional therapy in CLL patients has been also tested by Mauro et $\mathrm{al}^{77}$ In this trial 19 older CLL patients ( $\geq 60$ years) in PR after first-line treatment with 6 monthly courses of chlorambucil $\left(10 \mathrm{mg} / \mathrm{m}^{2} /\right.$ day, days $1-5$ ) and prednisone (25 $\mathrm{mg} / \mathrm{m}^{2} /$ day, days $\left.1-5\right)$ received 4-weekly doses of rituximab $\left(375 \mathrm{mg} / \mathrm{m}^{2}\right)$. In 13/19 cases $(68 \%)$ rituximab produced an upgrade of the previous response from $\mathrm{PR}$ to $\mathrm{CR}$ and 2 of the 13 (15\%) patients who achieved a CR showed a cytometric CR. This study indicates that rituximab, given as post-remissional therapy in older
CLL patients treated with chlorambucil and prednisone produced a clinical benefit in the majority of cases. ${ }^{77}$ Several trials designed to evaluate the efficacy of consolidation and maintenance of rituximab therapy in CLL patients are ongoing.

Furthemore, recently the efficacy of rituximab as preparative regimen for non-myeloablative allogeneic bone marrow transplantation (allo-BMT) and as immunomanipulation in combination with donor lymphocyte infusion in patients with persistent or progressive CLL after allo-BMT has been evaluated. ${ }^{78}$ This study suggests that this type of immunomanipulation after transplant determines an increase of PFS. This is probably due to the improvement of the graft vs leukemia effect through ADCC and CDC stimulated by rituximab, ${ }^{79,80}$ or to the generation of specific cytotoxic $\mathrm{T}$ cells induced by anti-CD20 antibody, which may promote uptake and cross-presentation of cell-derived peptides by antigen-presenting dendritic cells. ${ }^{81}$

Finally a myriad of monoclonal antibodies with different specificities is in preclinical or early clinical investigation. Some of these have been designed to target the CD20 antigen, like rituximab. Ofatumumab, a fully humanized, high-affinity monoclonal antibody directed to an epitope on CD20 different from the rituximab binding epitope, is most advanced in clinical development. Ofatumumab has higher affinity for CD20 and activates CDC more effectively than rituximab. ${ }^{82,83} \mathrm{~A}$ registration study of this monoclonal antibody in refractory CLL patients and a phase II study in which ofatumumab is administered in combination with fludarabine and cyclophosphamide as frontline therapy are ongoing.

\section{Toxicity}

The majority of patients $(\sim 80 \%)$ treated with rituximab have shown at least one adverse event. ${ }^{34}$ In patients with low grade NHL who received rituximab alone the most common side effects were infusion-related reactions. These adverse effects were usually of mild or moderate severity (grade 1-2), of brief duration and observed during the first infusion. Grade 1-2 flu-like symptoms such as fever, chills and rigors occur in most patients during first infusion, although the incidence of infusion-related adverse events decreases with subsequent infusions. ${ }^{34}$ Infusion-related adverse effects occur within the first 30 minutes to 2 hours of starting the first infusion and usually are reversible with interruption or discontinuation of rituximab along with supportive care. Approximately $10 \%$ of patients showed a severe (grade 3-4) infusion-related reaction which may be accompanied by bronchospasm, hypotension, angioedema 
and/or hypoxia. ${ }^{34}$ Patients who develop cytokine release syndrome associated with tumor lysis syndrome may present renal, respiratory or multi-organ failure. Infusion-related deaths have been rare $(0.04 \%-0.07 \%$ of patients $)$. Patients at high-risk of developing severe adverse events are those with high lymphocyte counts $\left(\geq 25,000 \mathrm{~mm}^{3}\right)$ as well as patients with a high tumor burden (eg, bulky disease with lesions $\geq 10 \mathrm{~cm}$ ). Severe lymphopenia occurs in about $40 \%$ of patients, although it does not appear to be associated with adverse consequences. ${ }^{34}$

Interestingly, in the dose-escalation study reported by O'Brien et al, rituximab doses of 500 to $1500 \mathrm{mg} / \mathrm{m}^{2}$ were associated with minimal adverse events. ${ }^{11}$ At a dosage level of $2250 \mathrm{mg} / \mathrm{m}^{2}, 8 / 12$ patients showed grade 1 or 2 events, but no patients developed severe adverse reactions. Moreover 1/40 patients with CLL developed grade 3 or 4 adverse events compared with $5 / 10$ with other diagnoses $(2.5 \%$ vs $50 \%, P<0.001) .{ }^{11}$ To minimize the infusion-related toxicity Byrd et al administered $100 \mathrm{mg}$ on day 1 and subsequently $375 \mathrm{mg} / \mathrm{m}^{2}{ }^{12}$ Thirteen patients (39\%) developed transient, cytokine-associated infusion toxicity that resolved by the third infusion. ${ }^{12}$ Since tumor lysis syndrome and deaths have been reported in patients with high circulating tumor load due to the high levels of cytokines released, it is suitable for patients with lymphocyte counts $\geq 25,000 \mathrm{~mm}^{3}$ where in the first treatment cycle the dosage of rituximab is split and given on two consecutive days or administering $100 \mathrm{mg}$ of rituximab on day 1 the remainder of the dose on day 2. All patients have to be premedicated with $25 \mathrm{mg}$ of iv diphenhydramine and oral acetaminophen.

\section{Conclusion}

In the past decade the most important advances in the treatment of CLL patients have been the demonstration of improvement in outcome with chemoimmunotherapy. Today, for CLL cases with good performance status the treatment of choice is the FCR schedule. As initially shown by the MDACC group and subsequently confirmed by the German CLL group, the FCR schedule enabled a high CR rate to be achieved, with MRD being eradicated in a high percentage of patients. ${ }^{15,16,20}$ Moreover these studies highlighted the importance of achieving CR and eradicating MRD in CLL, since these patients had a longer duration of response than patients with residual disease. The German CLL group study (CLL8 study) led to the approval of rituximab in combination with chemotherapy for CLL in both the US and Europe. Since FCR is associated with significant hematologic toxicities, a dose-reduced version of FCR (FCR-Lite) and a sequential schedule $\left(\mathrm{F}>\mathrm{C}>\mathrm{R}>\right.$ ) have been evaluated. ${ }^{25,26}$ Although these schedules seem to be equally efficacious and safe, only randomized trials will ascertain whether these regimens are better than FCR in terms of response and toxicity. Since patients with elevated serum beta- 2 microglobulin achieved lower CR rate and shorter PFS when treated with frontline chemoimmunotherapy (FCR), for this subgroup of high-risk patients a trial to evaluate the safety and efficacy of FCR combined with alemtuzumab is ongoing at the MDACC. Recently, promising results have been reported with the addition of another monoclonal antibody, lumiliximab, to the FCR schedule. ${ }^{69}$ This schedule enabled a high CR rate to be achieved, and did not seem to enhance toxicity in previously treated patients with CLL. ${ }^{69}$ Furthermore, promising results are expected for the subset of unfit patients from two ongoing trials which are evaluating the efficacy and safety of a combination treatment of rituximab with chlorambucil.

A variety of monoclonal antibodies with different specificities is in several stages of preclinical or early clinical investigation. Some of these have been designed, like rituximab, to target the CD20 surface antigen. Among monoclonal antibodies, ofatumumab (anti-CD20) is the most advanced in clinical development. A phase III registration study of ofatumumab in alkylator-, fludarabine-, and alemtuzumabresistant CLL is nearing completion. Thus, monoclonal antibody therapy represents a field of highly promising future investigation in CLL and will, we hope, lead to a greater understanding of how best to use existing antibodies and to the introduction of new antibodies.

\section{Acknowledgments/disclosures}

Supported in part by Fondazione 'Amelia Scorza' onlus, Cosenza, Italy. We thank Brigida Gulino for precious secretarial assistance.

The authors disclose no conflicts of interest in relation to this work.

\section{References}

1. Redaelli A, Laskin BL, Stephens JM, et al. The clinical and epidemiological burden of chronic lymphocytic leukaemia. Eur J Cancer Care. 2004;13:279-287.

2. Catovsky D, Foa R. The Lymphoid Leukaemias. London: Butterworths; 1990.

3. Mauro FR, Foa R, Giannarelli D, et al. Clinical characteristics and outcome of young chronic lymphocytic leukemia patients: a single institution study of 204 cases. Blood. 1999;94:448-454.

4. Grever MR, Kopecky KJ, Coltman CA, et al. Fludarabine monophosphate: a potentially useful agent in chronic lymphocytic leukemia. Nouv Rev Fr Hematol. 1988;30:457-459. 
5. Keating MJ, O'Brien S, Lerner S, et al. Long-term follow-up of patients with chronic lymphocytic leukemia (CLL) receiving fludarabine regimens as initial therapy. Blood. 1998;92:1165-1171.

6. Johnson S, Smith AG, Loffler H, et al. Multicentre prospective randomised trial of fludarabine versus cyclophosphamide, doxorubicin and prednisone (CAP) for treatment of advanced-stage chronic lymphocytic leukaemia. The French Cooperative Group on CLL. Lancet. 1996;347:1432-1438.

7. Rai KR, Peterson BL, Appelbaum FR, et al. Fludarabine compared with chlorambucil as primary therapy for chronic lymphocytic leukemia. N Engl J Med. 2000;343:1750-1757.

8. Leporrier M, Chevret S, Cazin B, et al. Randomized comparison of fludarabine, $\mathrm{CAP}$, and $\mathrm{CHOP}$ in 938 previously untreated stage $\mathrm{B}$ and $\mathrm{C}$ chronic lymphocytic leukemia patients. Blood. 2001;98:2319-2325.

9. Huhn D, Von Schilling C, Wilhelm M, et al. Rituximab therapy of patients with B-cell chronic lymphocytic leukemia. Blood. 2001;98:1326-1331.

10. Hainsworth JD, Litchy S, Barton JH, et al. Single-agent rituximab as first-line and maintenance treatment for patients with chronic lymphocytic leukemia or small lymphocytic lymphoma: a phase II trial of the Minnie Pearl Cancer Research Network. J Clin Oncol. 2003;21:1746-1751

11. O'Brien SM, Kantarjian H, Thomas DA, et al. Rituximab doseescalation trial in chronic lymphocytic leukemia. $J$ Clin Oncol. 2001;19:2165-2170.

12. Byrd JC, Murphy T, Howard RS, et al. Rituximab using a thrice weekly dosing schedule in B-cell chronic lymphocytic leukemia and small lymphocytic lymphoma demonstrates clinical activity and acceptable toxicity. J Clin Oncol. 2001;19:2153-2164.

13. Byrd JC, Peterson BL, Morrison VL, et al. Randomized phase 2 study of fludarabine with concurrent versus sequential treatment with rituximab in symptomatic, untreated patients with chronic lymphocytic leukemia: results from Cancer and Leukemia Group B 9712 (CALGB 9712). Blood. 2003;119:976-984.

14. Byrd JC, Rai K, Peterson BL, et al. The addition of rituximab to fludarabine may prolong progression-free survival and overall survival in patients with previously untreated chronic lymphocytic leukemia: an updated retrospective comparative analysis of CALGB 9712 and CALGB 9011. Blood. 2005;105:49-53.

15. Keating MJ, O'Brien S, Albitar M, et al. Early results of a chemoimmunotherapy regimen of fludarabine, cyclophosphamide, and rituximab as initial therapy for chronic lymphocytic leukemia. J Clin Oncol. 2005;23:4079-4088

16. Wierda W, O'Brien S, Wen S, et al. Chemoimmunotherapy with fludarabine, cyclophosphamide, and rituximab for relapsed and refractory chronic lymphocyticleukemia. J Clin Oncol. 2005;23:4070-4078.

17. Byrd JC, Gribben JG, Peterson BL, Grever MR, Lozanski G, Lucas DM, et al. Select high-risk genetic features predict earlier progression following chemoimmunotherapy with fludarabine and rituximab in chronic lymphocytic leukemia: justification for risk-adapted therapy. $J$ Clin Oncol. 2006;24:437-443.

18. Schulz H, Klein SK, Rehwald U, Reiser M, Hinke A, Knauf WU, et al. Phase 2 study of a combined immunochemotherapy using rituximab and fludarabine in patients with chronic lymphocytic leukemia. Blood. 2002;100:3115-3120.

19. Tam CS, O'Brien S, Wierda W, et al. Long-term results of the fludarabine, cyclophosphamide, and rituximab regimen as initial therapy of chronic lymphocytic leukemia. Blood 2008;112:975-980.

20. Hallek M, Fingerle-Rowson G, Fink AM, et al. First-line treatment with fludarabine (F), cyclophosphamide (C), and rituximab (R) (FCR) improves overall survival (OS) in previously untreated patients (pts) with advanced chronic lymphocytic leukemia (CLL): results of a randomized phase III trial on behalf of an international group of investigators and the German CLL Study Group. [abstract] Blood. $2009 ; 535 \mathrm{a}$
21. Foon KA, Boyiadzis M, Land SR, et al. Chemoimmunotherapy with low-dose fludarabine and cyclophosphamide and high dose rituximab in previously untreated patients with chronic lymphocytic leukemia. J Clin Oncol. 2009;27:498-503.

22. Lamanna N, Jurcic JG, Noy A, et al. Sequential therapy with fludarabine, high-dose cyclophosphamide, and rituximab in previously untreated patients with chronic lymphocytic leukemia produces high-quality responses: molecular remissions predict for durable complete responses. J Clin Oncol. 2009;27:491-497.

23. Bosch F, Abrisqueta P, Villamor N. Rituximab, fludarabine, cyclophosphamide, and mitoxantrone: a new, highly active chemoimmunotherapy regimen for chronic lymphocytic leukemia.J Clin Oncol. 2009;27:4578-4584.

24. Faderl S, Wierda W, O'Brien S, Ferrajoli A, Lerner S, Keating MJ. Fludarabine, cyclophosphamide, mitoxantrone plus rituximab (FCM-R) in frontline CLL < 70 years. Leuk Res. 2010;34:284-288.

25. Lamanna N, Kalaycio M, Maslak P, et al. Pentostatin, cyclophosphamide, and rituximab is an active, well-tolerated regimen for patients with previously treated chronic lymphocytic leukemia. J Clin Oncol. 2006;24:1575-1781.

26. Kay NE, Geyer SM, Call TG, et al. Combination chemoimmunotherapy with pentostatin, cyclophosphamide, and rituximab shows significant clinical activity with low accompanying toxicity in previously untreated B chronic lymphocytic leukemia. Blood. 2007;109: $405-411$.

27. Shanafelt TD, Lin T, Geyer SM, et al. Pentostatin, cyclophosphamide, and rituximab regimen in older patients with chronic lymphocytic leukemia. Cancer. 2007;109:2291-2298.

28. Reff ME, Carner K, Chambers KS, et al. Depletion of B cells in vivo by a chimeric mouse human monoclonal antibody to CD20. Blood. 1994;83:435-445.

29. Anderson KC, Bates MP, Slaughenhoupt BL, et al. Expression of human B cell-associated antigens on leukemias and lymphomas: a model of human B cell differentiation. Blood. 1984;63:1424-1433.

30. Nadler LM, Ritz J, Hardy R, et al. A unique cell surface antigen identifying lymphoid malignancies of B cell origin. $J$ Clin Invest. 1981;67:134-140.

31. Petryk M, Grossbard ML. Rituximab therapy of B-cell neoplasms. Clin Lymphoma. 2000;1:186-194.

32. Almasri NM, Duque RE, Iturraspe J, et al. Reduced expression of CD20 antigen as a characteristic marker for chronic lymphocytic leukemia. Am J Hematol. 1992;40:259-263.

33. Beum PV, Lindorfer MA, Beurskens F, et al. Complement activation on B lymphocytes opsonized with rituximab or ofatumumab produces substantial changes in membrane structure preceding cell lysis. J Immunol. 2008; 181:822-832.

34. Plosker GL, Figgitt DP. Rituximab: a review of its use in nonHodgkin's lymphoma and chronic lymphocytic leukaemia. Drugs. 2003;63:803-843.

35. Maloney DG, Smith B, Rose A. Rituximab: mechanism of action and resistance. Semin Oncol. 2002;29(1 Suppl 2):2-9.

36. Cartron G, Dacheux L, Salles G, et al. Therapeutic activity of humanized anti-CD20 monoclonal antibody and polymorphism in IgG Fc receptor FcgammaRIIIa gene. Blood. 2002;99:754-8.

37. Carlotti E, Palumbo GA, Oldani E, et al. FcgammaRIIIA and FcgammaRIIA polymorphisms do not predict clinical outcome of follicular non-Hodgkin's lymphoma patients treated with sequential CHOP and rituximab. Haematologica. 2007;92:1127-1130.

38. Alas S, Emmanouilides C, Bonavida B. Inhibition of interleukin 10 by rituximab results indown-regulation of bcl-2 and sensitization of B-cell non-Hodgkin's lymphoma to apoptosis. Clin Cancer Res. 2001;7:709-723.

39. McLaughlin P, Grillo-Lopez AJ, Link BK, et al. Rituximab chimeric anti-CD20 monoclonal antibody therapy for relapsed indolent lymphoma: half of patients respond to a four-dose treatment program. J Clin Oncol. 1998;16:2825-2833. 
40. Daydé D, Ternant D, Ohresser M, et al. Tumor burden influences exposure and response to rituximab: pharmacokinetic-pharmacodynamic modeling using a syngeneic bioluminescent murine model expressing human CD20. Blood. 2009;113:3765-3772.

41. Fust G, Czink E, Minh D, et al. Depressed classical complement pathway activities in chronic lymphocytic leukemia. Clin Exp Immunol. 1985;60:489-495

42. Klepfish A, Gilles L, Ioannis K, Eliezer R, Ami S. Enhancing the action of rituximab in chronic lymphocytic leukemia by adding fresh frozen plasma: complement/rituximab interactions and clinical results in refractory CLL. Ann N Y Acad Sci. 2009;1173:865-873.

43. Maloney DG, Liles TM, Czerwinski DK, et al. Phase I clinical trial using escalating single-dose infusion of chimeric anti-CD20 monoclonal antibody (IDEC-C2B8) in patients with recurrent B-cell lymphoma. Blood. 1994;84:2457-2466.

44. Maloney DG, Grillo-Lopez AJ, Bodkin DJ, et al. IDECC2B8: results of a phase I multiple-dose trial in patients with relapsed non-Hodgkin's lymphoma. J Clin Oncol. 1997;15:3266-3274.

45. Maloney DG, Grillo-Lopez AJ, White CA, et al. IDECC2B8 (Rituximab) anti-CD20 monoclonal antibody therapy in patients with relapsed lowgrade non-Hodgkin's lymphoma. Blood. 1997;90:2188-2195.

46. Grillo-Lopez AJ. Rituximab: an insider's historical perspective. Semin Oncol. 2000;27:9-16.

47. McLaughlin P, White CA, Grillo-Lopez AJ, Maloney DG. Clinical status and optimal use of rituximab for B-cell lymphomas. Oncology (Williston Park). 1998;12:1763-1769.

48. Nguyen DT, Amess JA, Doughty H, Hendry L, Diamond LW. IDECC2B8 anti-CD20 (rituximab) immunotherapy in patients with low-grade non-Hodgkin's lymphoma and lymphoproliferative disorders: evaluation of response on 48 patients. Eur J Haematol. 1999;62:76-82.

49. Winkler U, Jensen M, Manzke O, Schulz H, Diehl V, Engert A. Cytokine-release syndrome in patients with B-cell chronic lymphocytic leukemia and high lymphocyte counts after treatment with an anti-CD20 monoclonal antibody (rituximab, IDEC-C2B8). Blood. 1999;94:2217-2224.

50. Ladetto M, Bergui L, Ricca I, Campana S, Pileri A, Tarella C. Rituximab anti-CD20 monoclonal antibody induces marked but transient reductions of peripheral blood lymphocytes in chronic lymphocytic leukaemia patients. Med Oncol. 2000;17:203-210.

51. Itala M, Geisler CH, Kimby E, et al. Standard-dose anti-CD20 antibody rituximab has efficacy in chronic lymphocytic leukaemia: results from a Nordic multicentre study. Eur J Haematol. 2002;69:129-134.

52. Thomas D, O'Brien S, Giles FJ, et al. Single agent rituxan in early stage chronic lymphocytic leukemia (CLL). [abstract] Blood. 2001;98:364a.

53. Byrd JC, Smith L, Hackbarth ML, Flinn IW, Young D, Proffitt JH, et al. Interphase cytogenetic abnormalities in chronic lymphocytic leukemia may predict response to rituximab. Cancer Res. 2003;63:36-38.

54. O'Brien SM, Kantarjian HM, Cortes J, et al. Results of the fludarabine and cyclophosphamide combination regimen in chronic lymphocytic leukemia. J Clin Oncol. 2001;19:1414-1420.

55. Tsimberidou AM, Tam C, Abruzzo LV, et al. Chemoimmunotherapy may overcome the adverse prognostic significance of $11 \mathrm{q}$ deletion in previously untreated patients with chronic lymphocytic leukemia. Cancer. 2009;115:373-80.

56. Lin KI, Tam CS, Keating MJ, et al. Relevance of the immunoglobulin VH somatic mutation status in patients with chronic lymphocytic leukemia treated with fludarabine, cyclophosphamide, and rituximab (FCR) or related chemoimmunotherapy regimens. Blood 2009;113:3168-71.

57. Knauf WU, Lissichkov T, Aldaoud A, et al. Phase III randomized study of bendamustine compared with chlorambucil in previously untreated patients with chronic lymphocytic leukemia. J Clin Oncol. 2009;10; $27: 4378-84$

58. Fischer K, Cramer P, Stilgenbauer S, et al. Bendamustine combined with rituximab (BR) in first-line therapy of advanced CLL: a multicenter phase II trial of the German CLL Study Group (GCLLSG). [abstract] Blood. 2009; 114:205a.
59. Castro JE, James DF, Sandoval-Sus JD, Jain S, Bole J, Rassenti L, Kipps TJ. Rituximab in combination with high-dose methylprednisolone for the treatment of chronic lymphocytic leukemia. Leukemia. 2009;23:1779-1789.

60. Shan D, Ledbetter JA, Press OW. Signaling events involved in anti20-induced apoptosis of malignant human B cells. Cancer Immunol Immunother. 2000;48:673-683.

61. Hofmeister JK, Cooney D, Coggeshall KM. Clustered CD20 induced apoptosis: src-family kinase, the proximal regulator of tyrosine phosphorylation, calcium influx, and caspase 3-dependent apoptosis. Blood Cells Mol Dis. 2000;26:133-143.

62. Golay J, Zaffaroni L, Vaccari T, Lazzari M, Borleri GM, Bernasconi S, et al. Biologic response of B lymphoma cells to anti-CD20 monoclonal antibody rituximab in vitro: CD55 and CD59 regulate complementmediated cell lysis. Blood. 2000;95:3900-3908.

63. Tangye SG, Raison RL. Human cytokines suppress apoptosis of leukaemic CD5+ B cells and preserve expression of bcl-2. Immunol Cell Biol. 1997;75: 127-135.

64. Adami F, Guarini A, Pini M, Siviero F, Sancetta R, Massaia M, et al. Serum levels of tumour necrosis factor-alpha in patients with B-cell chronic lymphocytic leukaemia. Eur J Cancer. 1994;30A: 1259-1263.

65. Woyach JA, Lin TS, Lucas MS, et al. A phase I/II study of rituximab and etanercept in patients with chronic lymphocytic leukemia and small lymphocytic lymphoma. Leukemia. 2009;23:912-918.

66. Lundin J,Osterborg A, Brittinger G, et al. CAMPATH-1H monoclonal antibody in therapy for previously treated low-grade non-Hodgkin's lymphomas: a phase II multicenter study. J Clin Oncol. 1998;16: 3257-3263.

67. Faderl S, Thomas DA, O’Brien S, et al. Experience with alemtuzumab plus rituximab in patients with relapsed and refractory lymphoid malignancies. Blood. 2003;101:3413-3415.

68. Zent CS, Call TG, Shanafelt TD, et al. Early treatment of high-risk chronic lymphocytic leukemia with alemtuzumab and rituximab. Cancer. 2008;113:2110-2118.

69. Wierda WG, O’Brien S, Faderl S, Ferrajoli A, Ravandi-Kashani F, Cortes J, et al. Combined cyclophosphamide, fludarabine, alemtuzumab, and rituximab (CFAR), an active regimen for heavily treated patients with CLL. [abstract] Blood. 2006;108:14a.

70. Wierda WG, O’Brien S, Ferrajoli A, et al. Combined Cyclophosphamide, Fludarabine, Alemtuzumab, and Rituximab (CFAR), an Active Frontline Regimen for High-Risk Patients with CLL. [abstract] Blood. 2007; 110:628a

71. Byrd JC, Kipps TJ, Flinn IW, et al. Phase $1 / 2$ study of lumiliximab combined with fludarabine, cyclophosphamide, and rituximab in patients with relapsed or refractory chronic lymphocytic leukemia. Blood. 2010;115:489-495.

72. Catovsky D, Richards S, Matutes E, et al. Assessment of fludarabine plus cyclophosphamide for patients with chronic lymphocytic leukaemia (the LRF CLL4 Trial): a randomised controlled trial. Lancet. 2007;370:230-239.

73. Eichhorst BF, Busch R, Stilgenbauer S, et al. First-line therapy with fludarabine compared with chlorambucil does not result in a major benefit for elderly patients with advanced chronic lymphocytic leukemia. Blood. 2009; 114:3382-3391.

74. Ghielmini M, Schmitz SF, Cogliatti SB, et al. Prolonged treatment with rituximab in patients with follicular lymphoma significantly increases event-free survival and response duration compared with the standard weekly x 4 schedule. Blood. 2004;103:4416-4423.

75. Hainsworth JD, Lichty S, Shaffer DW, et al. Maximizing therapeutic benefit of rituximab maintenance therapy versus re-treatment at progression in patients with indolent non-Hodgkin's lymphoma - a randomized phase II trial of the Minnie Pearl Cancer Research Network. J Clin Oncol. 2005;23:1088-1095

76. Del Poeta G, Del Principe MI, Ragusa D, et al. Rituximab maintenance following chemoimmunotherapy improves outcome in B-cell chronic lymphocytic leukemia. [abstract] Blood. 2009;114:2364a. 
77. Mauro FR, Del Giudice I, Gentile M, et al. Post-remissional rituximab administration for the treatment of older chronic lymphocytic leucemia (CLL) patients responsive to first-line therapy with chlorambucil and prednisone. [abstract] Haematologica. 2007;44:124a.

78. Khouri IF, Saliba RM, Admirand J, et al. Graft-versus leukaemia effect after non-myeloablative haematopoietic transplantation can overcome the unfavourable expression of ZAP-70 in refractory chronic lymphocytic leukaemia. Br J Haematol. 2007;137:355-363.

79. Clynes RA, Towers TL, Presta LG, Ravetch JV. Inhibitory Fc receptors modulate in vivo toxicity against tumor targets. Nat Med. 2000;6:443-446

80. Pfeiffer M, Stanojevic S, Feuchtinger T, Greil J, et al. Rituximab mediates in vitro antileukemic activity in pediatric patients after allogeneic transplantation. Bone Marrow Transplant. 2005;36:91-97.
81. Hsu FJ, Komarovskaya M. CTLA4 blockade maximizes antitumor T-cell activation by dendritic cells presenting idiotype protein or opsonized anti-CD20 antibody-coated lymphoma cells. J Immunother. 2002;25:455-468.

82. Teeling JL, Mackus WJ, Wiegman LJ, et al. The biological activity of human CD20 monoclonal antibodies is linked to unique epitopes on CD20. J Immunol. 2006;177:362-371.

83. Teeling JL, French RR, Cragg MS, et al. Characterization of new human CD20 monoclonal antibodies with potent cytolytic activity against non-Hodgkin lymphomas. Blood. 2004;104:1793-1800.

\section{Publish your work in this journal}

Cancer Management and Research is an international, peer-reviewed open access journal focusing on cancer research and the optimal use of preventative and integrated treatment interventions to achieve improved outcomes, enhanced survival and quality of life for the cancer patient The journal welcomes original research, clinical \& epidemiological studies, reviews \& evaluations, guidelines, expert opinion \& commentary, case reports \& extended reports. The manuscript management system is completely online and includes a very quick and fair peerreview system, which is all easy to use. Visit http://www.dovepress.com/ testimonials.php to read real quotes from published authors.

Submit your manuscript here: http://www.dovepress.com/cancer-management-and-research-journal 